\title{
Helicobacter Pylori Infections in Peptic Ulcer Perforations: A Retrospective Analysis in Two Referral Hospitals in Douala, Cameroon
}

\author{
Francois Adrien Morel Bokalli'1,2, Chi Fru McWright' ${ }^{1}$ Jerry Brown Njoh Aseneh", \\ Takere Maseoli Mbachan', Ngomba Divine Mokake3, \\ Jules Clément Assob Nguedia4, Marcelin Ngowe Ngowe $^{5}$
}

${ }^{1}$ Department of Medicine, Faculty of Health Sciences, University of Buea, Buea, Cameroon

${ }^{2}$ Laquintinie Hospital, Douala, Cameroon

${ }^{3}$ Department of Surgery, Faculty of Health Sciences, University of Buea, Buea, Cameroon

${ }^{4}$ Department of Biomedical Sciences, Faculty of Medicine and Pharmaceutical Sciences, University of Douala, Douala, Cameroon

${ }^{5}$ Department of Surgery, Faculty of Medicine and Pharmaceutical Sciences, University of Douala, Douala, Cameroon

Email: francois_boks@yahoo.fr, chimcwright@gmail.com, jbaseneh@gmail.com, mbachan_takere@yahoo.com,

divymoks2001@yahoo.fr, juleclement@yahoo.fr, nkouki2002@yahoo.fr

How to cite this paper: Bokalli, F.A.M., McWright, C.F., Aseneh, J.B.N., Mbachan, T.M., Mokake, N.D., Nguedia, J.C.A. and Ngowe, M.N. (2020) Helicobacter Pylori Infections in Peptic Ulcer Perforations: A Retrospective Analysis in Two Referral Hospitals in Douala, Cameroon. Surgical Science, 11, 298-311.

https://doi.org/10.4236/ss.2020.1110032

Received: September 17, 2020

Accepted: October 25, 2020

Published: October 28, 2020

Copyright $\odot 2020$ by author(s) and Scientific Research Publishing Inc. This work is licensed under the Creative Commons Attribution International License (CC BY 4.0).

http://creativecommons.org/licenses/by/4.0/

\begin{abstract}
Background: Perforations are major complications of peptic ulcer disease and surgical emergencies with important mortality and morbidity. Helicobacter pylori ( $H$. pylori) has been identified as one of the commonest factors associated with peptic ulcer disease. However, little is known about its implication in cases of perforations in Cameroon. We aimed to determine the frequency of Helicobacter pylori infections in cases of perforated peptic ulcers, describe clinical features and outcomes of these cases in Cameroon. Method: A hospital-based retrospective cross-sectional study was conducted through the review of patients' records admitted for peptic ulcer perforations in Laquintinie and Douala General Hospitals over a period of 5 years (January 2014 - December 2018). We defined H. pylori infection as; positive result on tissue biopsy at time of surgery. We used SPSS version 23.0 to analyse data and set an alpha value at $\mathrm{P}=0.05$. Results: We reviewed 115 cases of peptic ulcer perforation, with a mean age of 40 years and sex ratio (M:F) of 5:1. All patients underwent emergency laparotomy, 48 (41\%) cases had a biopsy report and the prevalence of $H$. pylori infection in these cases was $47.9 \%$. Smoking, alcohol consumption and Non-Steroidal Anti-inflammatory Drugs (NSAIDs) use, were not associated with peptic ulcer perforation. The morbidity was at $43.7 \%$ and mortality at $14 \%$. Mortality was increasing with a higher Mannheim Peritonitis Index score (OR: 23.51, 95\% CI: 4.197 -
\end{abstract}


143.003, P-value: 0.000). Conclusion: We observed a high prevalence of $H$. pylori infection in patients with peptic ulcer perforations. We recommend systematic $H$. pylori screening in cases of perforations and that larger studies should be carried out to evaluate the association of $H$. pylori infection with peptic ulcer perforation in Sub-Saharan Africa.

\section{Keywords}

Perforated Peptic Ulcers, Helicobacter pylori Infections, Clinical Features, Outcome

\section{Introduction}

Peptic ulcer disease (PUD) refers to a break in the mucosal lining of the stomach or duodenum and occasionally the lower part of the oesophagus [1]. There are five major complications of PUD; bleeding, perforation, penetration, obstruction and malignancy [2].

In 1983, the whole thinking regarding the pathophysiology and management of this disease was revolutionized when Warren and Marshall [3] reported Helicobacter pylori (H. pylori) infection plays a crucial role in the pathogenesis of PUD. The revolution in PUD treatment that occurred with the discovery of the role of $H$. pylori is yet to lead to any detectable changes in incidence or treatment of peptic ulcer perforations (PUP) [4] [5].

As such, notable factors associated with PUP are; drugs (use of Non-Steroidal Anti Inflammatory Drugs (NSAIDs), steroids), smoking, fasting, stress, alcohol and gastrinoma [6].

PUP occurs in $2 \%-10 \%$ of patients with ulcer disease, it is the second most frequent complication after bleeding [7]. Gastroduodenal perforation, with leakage of alimentary contents into the peritoneal cavity, is a common surgical emergency associated with morbidity and mortality in $50 \%$ and $30 \%$ of cases respectively [8] [9]. PUP present as acute abdominal emergency conditions, with localized or generalized peritonitis and a high risk for further development of sepsis and death [10].

About $50 \%$ of the global population is colonized by $H$. pylori in the gastric mucosa, yet it causes diseases in only $10 \%-20 \%$. Nonetheless, it shows a variable prevalence $(0-90 \%)$ in perforated ulcers [5] [11]. In addition, studies done in Africa have shown that the rate of $H$. pylori infections in patients with PUP ranges from $50 \%-80 \%$ and $H$. pylori infections, as a risk factor for PUP, appear to be more relevant in younger patients [12] [13].

$H$. pylori is highly endemic in Cameroon [14] with a prevalence estimated at $72.5 \%$ with a slight male predominance and affecting the young adults of less than 40 years. It was also higher among people living in urban cities, with low level of education and of low socioeconomic status. The prevalence of $H$. pylori infections was $63 \%$ among patients with gastric ulcers and 50\% among those 
with duodenal ulcers [15].

Despite diagnostic and therapeutic advancements [16] [17], the role of $H . p y$ lori in the incidence of perforations and possible interactions with other known risks is yet to be ascertained. However, there is paucity of data regarding its burden in peptic ulcer perforations in Cameroon. Therefore, we sought to determine the influence of $H$. pylori infections in cases of peptic ulcer perforations in the city of Douala.

\section{Materials and Method}

\subsection{Study Area}

We carried out this study in two referral hospitals in Douala (the economic capital of Cameroon); the Douala General and Laquintine Hospitals. They host an extensive technical plateau and experimented specialists.

\subsection{Study Design}

This study was a hospital-based cross-sectional retrospective study carried out over a period from January 2014 - December 2018.

\subsection{Study Population}

We reviewed all records of patients hospitalized for peptic ulcer perforation in both hospitals from $1^{\text {st }}$ January 2014 to $31^{\text {st }}$ December 2018, excluded cases of perforations resulting from trauma and all cases managed conservatively (not surgically), as well as records with incomplete data. Where histopathology records were available, cases were classified as; infected with $H$. pylori if positive or not infected with $H$. pylori if negative.

\subsection{Study Procedure}

The study involved the use of patients' records who had been treated for PUP. Additional information was obtained from ward registers, histopathology reports and theatre records. Morbidity was considered as medical complications sustained postoperatively during the hospital stay. The Mannheim Peritonitis Index [18] was the scoring system used to predict outcome, we classified into 3 groups; those with a score $<21,21$ to 28 and $>28$ corresponding to mild, moderate and severe respectively. These were collected with the help of a pre-established data collection form (Appendix).

\subsection{Data Management and Analysis}

The Data collection forms were checked on a daily basis to ensure correct entry of information and codes used to ensure confidentiality. Data were keyed into a computer, secured by a password known only to the primary investigator. Data collected were entered into Census and Survey Processing System (CSpro) version 7.0. and exported for analysis into Statistical Package for Social Sciences (SPSS) IBM version 23.0. 
Data were summarized as frequencies and proportions for categorical variables. Continuous variables were summarized using means and standard deviation for parametric variables and median and interquartile range for nonparametric variables. Group comparison for categorical variables was done using Chi-square $\left(\chi^{2}\right)$ test and Fisher's exact test (where appropriate). The p-value < 0.05 was considered statistically significant.

The prevalence was determined by counting the number of patients in whom the bacteria were isolated divided by the overall number patients who were biopsied.

\subsection{Ethical Statement}

We obtained administrative clearance from the Faculty of Health Sciences of the University of Buea, followed by ethical clearance from the Institutional Review Board of the Faculty of Health Science. Then proceeded to obtain authorization from the administration of the Douala General and Laquintinie Hospitals.

\section{Results}

In, total, 176 cases of perforations were identified. 61 files were excluded (42 Traumatic perforations, 17 incomplete records and 2 conservatively managed). We retained 115 for analysis. 48 (41.2\%) benefitted from a biopsy amongst which the prevalence of $H$. pylori infection was $47.9 \%$ (Table 2). Their mean age was $40.0 \pm 16.5$ years and Sex ratio (M:F) was 5:1 (Table 1).

Out of the 48 screened cases, 45 cases $(93.8 \%)$ had gastric ulcer perforations,

Table 1. Age and gender distribution of study population.

\begin{tabular}{ccc}
\hline \multirow{2}{*}{ Variables } & \multicolumn{2}{c}{ Helicobacter pylori } \\
\cline { 2 - 3 } & Present (\%) & Absent (\%) \\
\hline Age groups (years) & $7(43.8)$ & $9(56.2)$ \\
$15-30$ & $11(68.8)$ & $5(31.2)$ \\
$31-45$ & $2(20)$ & $8(80)$ \\
$46-60$ & $3(50)$ & $3(50)$ \\
$60+$ & & $20(50)$ \\
Gender & $20(50)$ & $5(62.5)$ \\
Male & $3(37.5)$ & \\
Female & & \\
\hline
\end{tabular}

Table 2. Relationship between type of perforation and $H$. pylori status.

\begin{tabular}{ccccc}
\hline \multirow{2}{*}{ Site of perforation } & \multicolumn{2}{c}{ Helicobacter pylori } & \multirow{2}{*}{ Total } & P-value \\
\cline { 2 - 3 } & Present (\%) & Absent (\%) & & \\
\hline Gastric & $22(48.9)$ & $23(51.1)$ & $45(100)$ & 1.000 \\
Duodenal & $1(33.3)$ & $2(66.7)$ & $3(100)$ & \\
Total & $23(47.9)$ & $25(52.1)$ & $48(100)$ & \\
\hline
\end{tabular}


$22(48.9 \%)$ of which were positive for $H$. pylori infection while 3 cases $(6.2 \%)$ had duodenal ulcer perforations, 1 (33.3\%) of which was positive for $H$. pylori infection. $40 / 45$ (88.9\%) gastric ulcer perforation cases were pyloric perforations (Table 2).

Of the 11 with history of smoking, 5 were found to be $H$. pylori positive. Among 37 non-smokers, 18 were $H$. pylori positive. 24 persons had a known history of PUD or recurrent dyspepsia, among them 12 were $H$. pylori positive and among those with neither history, 11 were $H$. pylori positive. Among 11 patients with history of alcoholism, 8 were $H$. pylori positive and among 37 non alcoholics 15 had $H$. pylori infection. Among 15 patients with history of NSAIDs, 8 were positive for $H$. pylori and among 33 patients with no history of NSAIDs 15 tested positive for $H$. pylori. No significant association was found between the presence of $H$. pylori infection in peptic ulcer perforation with smoking, alcohol intake, history of PUD/dyspepsia or NSAIDS use (Table 3).

The median duration of hospital stay was 12.0 (9 - 18) days, which was shorter in the $H$. pylori negative population (median (IQR) $=10(7-17)$ days. The morbidity was $43.7 \%$, as 21 of the 48 cases developed some form of post-operative complication. Surgical site infection was the commonest complication among the $H$. pylori positive population and some developed two or more complications (Table 4).

The mortality in our study was $17 \%$ (7/48), with just one case registered as $H$. pylori positive. Mortality was found to be higher in patients with MPI greater than 29 compared to those with less $(\mathrm{p}=0.000)($ Table 5$)$.

\section{Discussion}

Of the 115 patients treated for PUP, 48 (42\%) were screened for the presence of $H$. pylori infection. This was relatively low and could be explained by financial

Table 3. Association of factors with $H$. pylori infection.

\begin{tabular}{|c|c|c|c|c|c|}
\hline \multirow{2}{*}{\multicolumn{2}{|c|}{ Factors }} & \multicolumn{2}{|c|}{ Helicobacter pylori } & \multirow{3}{*}{$\begin{array}{c}\text { Total } \\
24(100)\end{array}$} & \multirow{3}{*}{$\begin{array}{c}\text { P-value } \\
1.000\end{array}$} \\
\hline & & \multirow{2}{*}{$\begin{array}{c}\text { Present (\%) } \\
12(50)\end{array}$} & \multirow{2}{*}{$\begin{array}{c}\text { Absent (\%) } \\
12(50)\end{array}$} & & \\
\hline PUD/Dyspepsia & Present & & & & \\
\hline & Absent & $11(45.8)$ & $13(54.2)$ & $24(100)$ & \\
\hline \multirow[t]{2}{*}{ NSAIDs } & Present & $8(53.3)$ & $7(46.7)$ & $15(100)$ & 0.846 \\
\hline & Absent & $15(45.5)$ & $18(54.5)$ & $33(100)$ & \\
\hline \multirow[t]{2}{*}{ Smoking } & Present & $5(45.5)$ & $6(54.5)$ & $11(100)$ & 1.000 \\
\hline & Absent & $18(48.6)$ & $19(54.1)$ & $37(100)$ & \\
\hline \multirow[t]{2}{*}{ Alcohol } & Present & $8(72.7)$ & $3(27.3)$ & $11(100)$ & 0.125 \\
\hline & Absent & $15(40.5)$ & $22(59.5)$ & $37(100)$ & \\
\hline \multirow[t]{2}{*}{ Blood group $\mathrm{O}$} & Present & $10(50)$ & $10(50)$ & $20(100)$ & 1.000 \\
\hline & Absent & $13(46.4)$ & $15(53.6)$ & $28(100)$ & \\
\hline
\end{tabular}

PUD: peptic ulcer disease, NSAIDs: non steroidal anti inflammatory drug. 
Table 4. Follow-up and outcome in study population.

\begin{tabular}{ccc}
\hline Variable & \multicolumn{2}{c}{ Helicobacter pylori } \\
\cline { 2 - 3 } Hospital stay (days) & Present (\%) & Absent (\%) \\
$0-10$ & $9(41)$ & $13(59)$ \\
$11-20$ & $10(59)$ & $7(41)$ \\
$>20$ & $4(44)$ & $5(56)$ \\
Complication & & $5(56)$ \\
Surgical site infection & $4(44)$ & $4(80)$ \\
Respiratory infection & $1(20)$ & $6(86)$ \\
Septicemia & $1(14)$ & $0(0)$ \\
Renal failure & $2(100)$ & $2(50)$ \\
Cardiovascular & $2(50)$ & $3(100)$ \\
Enterocuteneous fistulae & $0(0)$ & $12(36)$ \\
MPI score & & $10(100)$ \\
$<21$ & $21(64)$ & $3(60)$ \\
21 - 28 & $0(0)$ &
\end{tabular}

MPI: Mannheim peritonitis index.

Table 5. Prognostic score (Mannheim Peritonitis Index) against Mortality.

\begin{tabular}{cccccc}
\hline MPI score & Death (\%) & Discharged (\%) & OR & CI & P-value \\
\hline$<21$ & $1(3)$ & $33(97)$ & & & \\
$21-28$ & $3(30)$ & $7(70)$ & & & \\
$>29$ & $3(75)$ & $1(25)$ & 23.51 & $4.19-143.00$ & $0.000^{\star}$ \\
\hline
\end{tabular}

MPI: Mannheim peritonitis index, OR: Odds ratio, CI: Confidence interval, ${ }^{\star}$ statistical significance.

constraints on the part of patients and a probable under-prescription on the part of the treating physician.

Among these 48 cases, 40 (83.3\%) were males (M:F ratio of 5:1). This finding was similar to results obtained by Bekele et al. in Nigeria and Afuwape et al. in Ethiopia [7] [19]. This is likely owing to the fact that men are the breadwinners in the family, and are consequently prone to stress, drugs and alcohol abuse.

The mean age at presentation was 40 years with an age range of 17 to 80 years. Afuwape et al. [19] reported a mean age of 42.5 years and the highest incidence in the fifth decade. These results differed from those of Ghosh et al. in India [10] who showed most (45.1\%) patients were in the 15 - 30 age group. In Europe however, majority (68\%) of patients belonged to a much older age group ( $>60$ years) [20]. These variations in the age may be attributed to the age at which the patients are exposed to various risk factors predisposing for peptic ulcer disease and subsequently perforation. 
Prevalence of $H$. pylori infection in peptic ulcer perforation in our study was 47.9\%. This was comparable to the study by John et al. probably due to a similar sample size [21] who had a prevalence rate of $46.9 \%$. The prevalence according to the study by Dogra et al. had a prevalence of $92 \%$ [22]. This discrepancy could be accounted for by the fact that other diagnostic methods were used in that study.

Although the age groups 15 - 30 and 31 - 45 had equal number of participants, the percentage of $31-45$ year positive for $H$. pylori infection was highest and agrees with the findings of Dogra et al. [22].

The association of $H$. pylori infection with gastric ulcer perforation was slightly more striking in that out of 43 cases of gastric ulcer perforation, $H$. $p y$ lori was detected in 22 cases (48.9\%). But was less striking in cases of duodenal ulcer perforations where 1 out of 3 (33.3\%) had H. pylori detected. These results were similar to the study of Rashim et al. [23] where $H$. pylori was isolated in $48.7 \%$ of gastric ulcer perforation.

Although treatment of patients with history of chronic dyspepsia should be individualized, a cost-effective initial approach is to test for $H$. pylori and treat the infection if the test is positive. If the $H$. pylori test is negative, empiric therapy with an acid suppressant is recommended. In our study, patients having history of dyspepsia had a high prevalence rate of 50\% though Ullah et al. had a higher prevalence at $87 \%$ [24]. The differences in cultures could be an explanation to this.

Only 15 had positive history of NSAIDS use. Among these 15, 8 were positive for H. pylori infection (53.34\%). 33 patients did not have any history of NSAIDs use, out of which 15 tested positive for $H$. pylori $45.5 \%$. This observation is similar to what Rehmani and colleagues had in his study [3].

Bateson et al. reported strong association between $H$. pylori infection and smoking while in this study the association of $H$. pylori infection with smoking in perforated peptic ulcer disease patients was not found to be significant [25].

Among 11 patients with history of alcoholism, 8 tested positives for $H$. pylori infection and among 37 non-alcoholics, 15 were $H$. pylori positive. The difference was not statistically significant $(\mathrm{p}=0.125)$. The study by Rashim and collaborators [23] showed inverse correlation between alcohol ingestion and presence of active $H$. pylori infection.

Duration of hospital stay was slightly higher in the $H$. pylori positive population who on average spent more time in the hospital compared to the $H$. pylori negative population. Prolonged hospital stay was seen to be associated with post-operative complications and some non-medical reasons (such as financial constraints).

The main complications observed were surgical site infection, respiratory infection and septicaemia. The reason for high rates of surgical site infection could be due to heavy contamination of the wound due to bacterial peritonitis.

The Mannheim peritonitis index is one of the simplest scoring systems in use 
that allows the surgeon to easily determine the outcome risk during initial surgery. In theory the lower the score the lower the chances of morbidity or mortality from peritonitis and this was seen in practice in our study as the mortality rate was $1 / 48(2 \%)$ for those with a score $<21$ and 6/48 (12.5\%) for those $>21$. Those who were $H$. pylori positive had a better prognosis of survival from perforation peritonitis as shown by a Mannheim peritonitis index $<21$ for a majority $(60 \%)$ when compared to $H$. pylori negative and over $91 \%$ among those who tested positive. This could help conclude that $H$. pylori infection does not worsen the prognosis in cases of perforated peptic ulcer as this observation attained statistical significance. The mortality rate was higher compared to similar studies [21] [22].

All the cases in which the bacteria were isolated were systematically placed on H. pylori eradication therapy for 2 weeks, but follow up on this was not documented.

\section{Study Limitations}

1) The retrospective nature of this work made retrieval of some important data that would have been added value to the study difficult.

2) We assumed that all patients entered during the study had been subject to a fairly standard treatment commensurate with the individual diagnosis. Inadequate treatment could have negatively impacted on outcome, yet it was not a subject of evaluation in this study.

\section{Conclusion}

Peptic ulcer perforations are common findings in the male population of the fourth and fifth decades of life. Also, gastric perforations were more common than duodenal. The prevalence of $H$. pylori infection in cases of peptic ulcer perforations in which histopathologic biopsies were done was $47.9 \%$. This is quite high given that $H$. pylori eradication therapy is systematically prescribed in PUD. However, smoking, NSAIDs use and alcohol ingestion were not associated with $H$. pylori infection.

\section{Recommendations}

Raise awareness on the importance of $H$. pylori screening in cases of peptic ulcer perforations.

To always send excised body tissues for histopathologic analysis.

\section{Authors Contributions}

BFAM participated in the conception, literature review, design of the study, data analysis and management. CFM participated in design of study, edition and revision of manuscript. JBNA participated in literature review and data analysis. MTM participated in drafting, editing and revising the manuscript for publication. MDN participated in drafting the topic, design of study and literature review. ANJC participated in conception of topic, study design, data management 
and analysis. NNM participated in study design and conception, data analysis, editing and revising the manuscript for publication.

\section{Acknowledgements}

We are grateful to the staff of the Douala General Hospital and Laquintinie Hospital for their entire support to this work and also to all persons who contributed to the end result of this research.

\section{Conflicts of Interest}

The authors declare no conflicts of interest regarding the publication of this paper.

\section{References}

[1] Roy, S. (2016) Clinical Study of Peptic Ulcer Disease. Asian Journal of Biomedical and Pharmaceutical Sciences, 6, 41-43.

[2] Milosavljevic, T., Kostić-Milosavljević, M., Jovanović, I. and Krstić, M. (2011) Complications of Peptic Ulcer Disease. Digestive Diseases, 29, 491-493.

https://doi.org/10.1159/000331517

[3] Rehmani, B. and Pathak, P. (2018) The Prevalence of Helicobacter pylori in Perforated Peptic Ulcer Disease. International Surgery Journal, 5, 1720-1723. https://doi.org/10.18203/2349-2902.isj20181405

[4] Metzger, J., Styger, S. and Sieber, C. (2001) Prevalence of Helicobacter pylori Infection in Peptic Ulcer Perforations. Swiss Medical Weekly, 131, 99-103.

[5] Svanes, C. (2000) Trends in Perforated Peptic Ulcer: Incidence, Etiology, Treatment, and Prognosis. World Journal of Surgery, 24, 277-283. https://doi.org/10.1007/s002689910045

[6] Søreide, K., Thorsen, K., Harrison, E.M., Bingener, J., Møller, M.H., et al. (2015) Perforated Peptic Ulcer. The Lancet, 386, 1288-1298.

https://doi.org/10.1016/S0140-6736(15)00276-7

[7] Bekele, A., Zemenfes, D., Kassa, S., Deneke, A., Taye, M. and Wondimu, S. (2017) Patterns and Seasonal Variations of Perforated Peptic Ulcer Disease: Experience from Ethiopia. The Annals of African Surgery, 14, 86-91.

https://doi.org/10.4314/aas.v14i2.7

[8] Weledji, E.P. and Ngowe, M.N. (2013) The Challenge of Intra-Abdominal Sepsis. International Journal of Surgery, 11, 290-295. https://doi.org/10.1016/j.ijsu.2013.02.021

[9] Moller, M.H., Adamsen, S., Thomsen, R.W. and Moller, A.M. (2011) Multicentre Trial of a Perioperative Protocol to Reduce Mortality in Patients with Peptic Ulcer Perforation. British Journal of Surgery, 98, 802-810.

https://doi.org/10.1002/bjs.7429

[10] Bikash, C.G., Ambar, G. and Gautam, G. (2018) Assessment of Recent Epidemiological Trends in Peptic Ulcer Perforation Patients in an Eastern Indian Tertiary Hospital. Asian Journal of Medical Science, 9, 68-75.

https://doi.org/10.3126/ajms.v9i6.20858

[11] Ndip, R.N., Malange, A.E., Akoachere, J.F.T., MacKay, W.G., Titanji, V.P.K. and Weaver, L.T. (2004) Helicobacter pylori Antigens in the Faeces of Asymptomatic Children in the Buea and Limbe Health Districts of Cameroon: A Pilot Study. 
Tropical Medicine and International Health, 9, 1036-1040. https://doi.org/10.1111/j.1365-3156.2004.01299.x

[12] Dakubo JCB, Naaeder SB, Clegg-Lamptey JN. (2009) Gastro-duodenal peptic ulcer perforation. East African Medical Journal, 86, 100-109.

https://doi.org/10.4314/eamj.v86i3.54964

[13] Chalya, P.L., Mabula, J.B., Koy, M., Mchembe, M.D., Jaka, H.M., Kabangila, R., et al. (2011) Clinical Profile and Outcome of Surgical Treatment of Perforated Peptic Ulcers in Northwestern Tanzania: A Tertiary Hospital Experience. World Journal of Emergency Surgery, 6, 31. https://doi.org/10.1186/1749-7922-6-31

[14] Ankouane, F., Noah, D.N., Enyime, F.N., Ndjollé, C.M., Djapa, R.N., Njoya, O., et al. (2015) Helicobacter pylori and Precancerous Conditions of the Stomach: The Frequency of Infection in a Cross-Sectional Study of 79 Consecutive Patients with Chronic Antral Gastritis in Yaoundé, Cameroon. Pan African Medical Journal, 20, 52. https://doi.org/10.11604/pamj.2015.20.52.5887

[15] Andoulo, F.A., Noah, D.N., Tagni-Sartre, M., Ndam, E.C.N. and Blackett, K.N. (2013) Epidemiology of Infection Helicobacter pylori in Yaoundé: Specificity of the African Enigma. Pan African Medical Journal, 16, 115. https://doi.org/10.11604/pamj.2013.16.115.3007

[16] Elnagib, E., Mahadi, S.E. and Ahmed, M. (2008) Perforated Peptic Ulcer in Khartoum. Khartoum Medical Journal, 1, 62-64.

[17] Higham, J., Kang, J.Y. and Majeed, A. (2002) Recent Trends in Admissions and Mortality Due to Peptic Ulcer in England: Increasing Frequency of Haemorrhage among Older Subjects. Gut, 50, 460-464. https://doi.org/10.1136/gut.50.4.460

[18] Ngowe, N.M., Toure, A., Mouafo, T.F.F., Chichom, A., Tchounzou, R., Ako-Egbe, L., et al. (2014) Prevalence and Risk Factors Associated with Post-Operative Infections in the Limbe Regional Hospital of Cameroon. The Open Surgery Journal, 8, $1-8$.

[19] Afuwape, O., Irabor, D.O. and Ayandipo, O. (2013) An Audit of Perforated Peptic Ulcer Disease in a Tropical Teaching Hospital. East and Central African Journal of Surgery, 18, 40-44.

[20] Thorsen, K., Soreide, J.A., Kvaloy, J.T., Glomsaker, T. and Soreide, K. (2013) Epidemiology of Perforated Peptic Ulcer: Age- and Gender-Adjusted Analysis of Incidence and Mortality. World Journal of Gastroenterology, 19, 347-354. https://doi.org/10.3748/wjg.v19.i3.347

[21] John, B., Mathew, P.B. and Chandran, C.V. (2017) Prevalence of Helicobacter pylori in Peptic Ulcer Perforation. International Surgery Journal, 4, 3350. https://doi.org/10.18203/2349-2902.isj20174494

[22] Dogra, B.B., Panchabhai, S., Rejinthal, S., Kalyan, S., Priyadarshi, S. and Kandari, A. (2014) Helicobacter pylori in Gastroduodenal Perforation. Medical Journal of Dr. D. Y. Patil Vidyapeeth, 7, 170. https://doi.org/10.4103/0975-2870.126331

[23] Rashim, P.M. and Vineed, S. (2019) Prevalence of Helicobacter pylori Infection in Patients with Gastric Ulcer Perforation Admitted in a Tertiary Care Centre. International Surgery Journal, 6, 898-902.

https://doi.org/10.18203/2349-2902.isj20190821

[24] Ullah, A., Ullah, S., Ullah, A., Sadiq, M.U.D. and Khan, M. (2007) Frequency of Helicobacter pylori in Patients Presented with Perforated Peptic Ulcer. Journal of Postgraduate Medical Institute, 21, 25-28.

[25] Bose, A.C., Kate, V., Ananthakrishnan, N. and Parija, S.C. (2007) Helicobacter py- 
lori Eradication Prevents Recurrence after Simple Closure of Perforated Duodenal Ulcer. Journal of Gastroenterology and Hepatology, 22, 345-348.

https://doi.org/10.1111/j.1440-1746.2006.04490.x

\section{List of Abbreviations}

H. pylori-Helicobacter pylori

MPI-Mannheim Peritonitis Index

NSAIDs-Non Steroidal Anti Inflammatory Drugs

PUD_Peptic Ulcer Disease

PUP-Peptic Ulcer Perforation

BFAM-Bokalli Francois Adrien Morel

CFM-Chi Fru McWright

JBNA-Jerry Brown Njoh Aseneh

MTM-Mbachan Takere Maseoli

MDN-Mokake Divine Ngomba

ANJC-Assob Nguedia Jules Clement

NNM-Ngowe Ngowe Marcelin 


\section{Appendix: Data Collection Form}

HELICOBACTER PYLORI INFECTIONS IN PEPTIC ULCER

PERFORATIONS: A RETROSPECTIVE ANALYSIS IN TWO REFERRAL HOSPITALS IN DOUALA CAMEROON.

A. Demographic Data: PLEASE FILL IN OR TICK $(\sqrt{ })$ THE APPROPRIATE ANSWER

1. Age (in years):

2. Gender: $\quad \square$ Male $\square$ Female

3. Occupation:

B. CLINICAL DATA: PLEASE FILL IN OR TICK $(\sqrt{ })$ THE APPROPRIATE ANSWER

1. Presenting complaint(s)

Tick

Duration

Abdominal pain

Abdominal distension/swelling

Not passed stools

Not passed flatus

Nausea/vomiting

Diarrhea

Fever

Others (specify)

C. PAST MEDICAL HISTORY PLEASE FILL IN OR TICK $(\sqrt{ })$ THE APPROPRIATE ANSWER

1. Past Illness

PUD

Recurrent epigastric pains

Family history of PUD

Abdominal malignancy

HTN (1) DM (2) HIV (3)
Tick 2. Drug History Tick NSAIDs

Aspirin

Steroids

Others (specify)

3. Previous surgical/radiological procedures Tick

4. Risk Factors Tick

Radiotherapy

Smoking (quantify)

Previous surgeries

Endoscopic procedures (fibroscopy)

Alcohol (quantify)

Blood group $\mathrm{O}$

Others (specify)

D. PHYSICAL EXAMINATION: PLEASE FILL IN OR TICK $(\sqrt{ })$ THE APPROPRIATE ANSWER

$\begin{array}{ll}\text { 1. Vital signs } & \text { 3. General exam Tick } \\ \text { Blood pressure } & \text { Pallor } \\ \text { Pulse } & \text { Altered mental state } \\ \text { Respiratory rate } & \text { Cold peripheries } \\ \text { Temperature } & \text { Anxious }\end{array}$

4. Abdominal Exam

Tick Abdominal distention Abdominal tenderness Rebound tenderness Guarding 


$$
\text { Urine output Others (specify) }
$$

2. Anthropometric Measurement

Weight

Height
Rigidity

Shifting dullness

Absent bowel sounds

Anterior tenderness on DRE

Others (specify)

E. PARACLINICAL INVESTIGATION AND MANAGEMENT: PLEASE FILL IN OR TICK $(\sqrt{ })$ THE APPROPRIATE ANSWER
1. Radiological studies
Chest X-ray
Tick Findings
Plain abdominal X-ray
Pneumoperitoneum
Intra-peritoneal fluid collection
Abdominal ultrasound
Free gas in the abdomen
Others (specify)
Others (specify)

2. Laboratory investigation(s) Findings

FBC (1), urea/creatinine (2)

serum electrolytes (3)

serum amylase (4) LFT (5)

3. Pre-Op diagnosis Tick

Localised peritonitis

4. Pre-Op duration Tick

Diffuse peritonitis

Less than 24 hours

24 hours or more

5. Site of Perforation

Tick Number(s)

Gastric perforation

Specific site

Duodenal perforation

Specific site

6. Histopathology Reports Tick

Biopsy performed

H. pylori isolated

7. Color of Exudate Tick

Clear

Purulent

Fecal

Bloody

8. Intra operative procedure

Name

9. Post-op complications

Tick

Wound infection/failure

Fecal fistula (enterocutaneous fistula) 
Paralytic ileus

Chest infection (lung abscess, pneumonia, ards)

Anastomotic leak

Post-op intra-abdominal collection

Multi organ failure

Burst abdomen

Abdominal compartment syndrome

Renal failure

Neurologic deficit

$\mathrm{MI}$ and cardiac failure

DVT/pulmonary embolism

Sub-phrenic/pelvic abscess

Others (specify)

10. Outcome

Tick

Death

Discharge

11. MPI score wise distribution

Tick

Score

$<21$

$21-28$

$>29$

12. Duration of hospital stay

13. H. pylori Eradication therapy 